\title{
PSYCHOLOGICAL STUDY OF GUILT FEELING
}

\author{
MOTOI OHE \\ Tokyo Metropolitan University
}

\begin{abstract}
An Story Completion Test (SCT) to measure guilt feeling was devised and administered to several groups ; 37 Christian students, 27 Tenriist students, 11 Buddhist students, 84 non-religion students and 40 delinquent boys. Factorial structure of guilt feeling was investigated by factor analysis method, which revealed 2 factors. They were "Illegality" and "Impulsiveness". Parents' child rearing attitude, personality and life attitude were taken as major factors of acquiring guilt feeling. The relationship between those 3 factors and guilt feeling measure was investigated respectively. Consistent relationships were gained concerning factors of personality and life attitude. But clear-cut relations were not found concerning child rearing factors. Those results were analyzed in many respects.
\end{abstract}

Guilt feeling has often been discussed in the clinical field. Some psychologists have taken it negatively and consider it harmful for the development of healthy personality. On the other hand, others take it positively and maintain that it is an important factor of socialization. This point is illustrated clearly in the symposium "The role of the concept of sin in psychotherapy " (Mowrer, et al. 1960). For example, A. Ellis holds that guilt feeling is the cause of neurosis and that one of the aims of psychotherapy is to get rid of it. However, E. J. Shoben points out the three roles of guilt feeling as follows; it serves as (a) the punishment for the transgression of moral codes, (b) the warning signal for misconduct, (c) the motive for conforming the misconduct to the moral norm. This contrast of opinion offers us a very interesting problem. However, some cultural anthropologists such as R. Benedict (1946) hold that Japan is not a "guilt culture" in which persons act according to the inner sense of guilt feeling, but that is rather a "shame culture" in which persons follow external sanctions. But as D. P. Ausubel (1955) points out, differences of the sense of guilt among individuals within a culture would be as great as or greater than differences among cultures. It seems more fruitful to investigate the problem of how guilt feeling is experienced and how it develops within a culture than simply to contrast it with shame.

The definition of guilt feeling in the present study is rather broad one in comparison with that of cultural anthropologist's ... Guilt may be conceptualized as a special kind of negative self-evaluation which occurs when an individual acknowledges that his behavior is at variance with a given moral value to which he feels obligated to conform.

Present study consists of two parts. The purposes of Part I are to make an investigation of that concerning which people feel guilty today, and then to construct a test for measuring the degree of guilt feeling that an individual has. The test devised is to be administered to several groups, Religion group, Non-religion group and Delinquent group. The differences of responses and sex differences are to be investigated. Factorial structure of guilt feeling is then revealed by factor analysis method.

The purpose of Part II is to analyse the process of acquiring guilt feeling. The way of child rearing has often been said to influence the process of acquiring guilt feeling. And the ways of expression of guilt will be affected by the types of personality and life attitude. The relationships between those three factors and the guilt feeling measure, the score of the devised 
test, are investigated in the present study.

\section{PART I}

1. Construction of the test of guilt feeling. Subjects. The subjects were 138 male students and 9 female students from Tokyo Metropolitan University, and 31 male students from Tokyo Theological College.

Procedure. Ss were asked to write about what and how they feel guilty by free description method. The instruction was as follows, "About what and to what extent do you feel guilty and in what situation? Please write as many as possible."

Result. Though a wide variety of responses were gained, some of them appeared frequently. As a result, common responses and similar ones were put together in 6 categories. They were as follows :

(1) Illegal conducts-murder, stealing.

(2) Transgression of public moralitymisconduct in public such as in a street car, park, etc.

(3) Troubling others-unkindness, contempt, unfaithfulness, misunderstanding.

(4) Personal affairs-laziness, irresponsibility, egocentricity, hypocrisy, cheating.

(5) Sex - sexual desire, masturbation.

(6) In relation with God-profanity, arrogance against God.

Number 6 was reported only by students of Theological College. It is so special and rare a response in Japanese society that it was excluded from further analysis.

As W. Allinsmith (1957) suggests, story completion test may be more effective to investigate morality or guilt feeling than ordinary yes-no-type questionnaire. Consequently Story Completion Test (SCT) consisted of 20 items were constructed according to the above classification. Three or four situations were chosen from each category to cover all the classifications.

The content of 20 items of SCT is as follows.

1. Mr. X went swimming with his friend. On their way home, his friend told him to steal a ride on a train. He...
2. Mr. X was on the train. He strongly felt like smoking, even though it was a prohibited section. He. . .

3. Mr. X was very tired on his way home from a picnic. Fortunately he got a seat on the train. While it became very crowded, an old man boarded the train. $\mathrm{He}$...

4. Mr. X went for a walk to a park. $\mathrm{He}$ wanted to sit down. Since the benches were dirty, he wanted to sit on the grass. But there was a sign which prohibited him from sitting on the grass. $\mathrm{He} \ldots$

5. When Mr. X was hurrying home, he was stopped by a red signal at an intersection. No car was in the intersection, and the signal did not change quickly. He...

6. In a final examination, Mr. $\mathrm{X}$ had some questions which were hard to solve. He noticed that his friends $\mathrm{A}$ and $\mathrm{B}$ were secretly reading their notebooks. He...

7. Mr. X made an excursion with classmates, While he was shopping at a souvenir store, he was late for the departure time where they were to meet. Consequently they could not come home on schedule. He...

8. Mr. X commited an error at a very important volley-ball game. Consequently they were brought to deuce. He ...

9. Mr. X went shopping. The store was so crowded that the clerk made a mistake and gave too much change to him. He ...

10. Mr. X made an appointment with his friend at 7 o'clock. But he was absorbed in watching television, and it might be hard to get there in time. $\mathrm{He} . .$.

11. Mr. X dropped in to a book-store. Then he happened to be interested in an erotic magazine. $\mathrm{He} . .$.

12. When $\mathrm{Mr} . \mathrm{X}$ is left in his room alone, he sometimes indulges in sexual thoughts. $\mathrm{He}$

13. Sometimes Mr. X feels strong desire for women. $\mathrm{He}$...

14. The cat bred kittens again. Mr. X was told to throw them into the river and he put them in a basket and left home. $\mathrm{He} .$.

15. Since $\mathrm{Mr}$. $\mathrm{X}$ lost his fountainpen, he felt inconvenience. One day he found a fairly good fountainpen on the strcet. $\mathrm{He}$... 
TABle 1

Number of subjects

\begin{tabular}{lrrr}
\hline \multicolumn{1}{c}{ Group } & $\mathrm{m}$ & $\mathrm{f}$ & Total \\
\hline C : Ghristian & 17 & 20 & 37 \\
$\mathrm{~T}:$ Tenrist & 20 & 7 & 27 \\
B : Buddhist & 9 & 2 & 11 \\
G : General non-religion & 44 & 34 & 78 \\
$\quad$ student & 40 & 0 & 40 \\
D : Delinquent & 130 & 63 & 193
\end{tabular}

TABLE 2

Group difference of $\mathbf{G}$ score

\begin{tabular}{l|rrrrrr|r}
\hline G score & G & T & B & Gf & Gm & D & Total \\
\hline High† & 32 & 14 & 7 & 23 & 16 & 5 & 97 \\
Low & 5 & 13 & 4 & 11 & 28 & 35 & 96 \\
& \multicolumn{5}{|c}{$\chi^{2}=43.05$} & $p<.005$ &
\end{tabular}

$\dagger$ In this study $S$ s were divided by median. $S$ s who got more $\mathrm{G}$ score than 3.40 were grouped as "High",

16. Community chest activities were carried out on some busy streets. Mr. X was about to indifferently pass by one of the charity boxes. Then he noticed a girl whom he cared for among the group. He...

17. Mr. A was very worried about his tone deafness. Mr. X carelessly told about it to his friends. He...

18. Mr. X has not finished the paper which he was asked to complete by the 15 th. He will be late for the deadline at this rate. $\mathrm{He} .$.

19. Mr. X was a first baseman in a baseball game. A batter hit a grounder and rushed into first base. The umpire called the runner out, but Mr. X's foot had been a little off the base. $\mathrm{He}$...

20. Mr. X asked his senior to find employment. His senior took trouble in finding employment, but he himself took the examination of some other company and passed it. $\mathrm{He}$... 2. Administration of the Test (SCT)

Subjects. Since the problem of guilt feeling has some relation to religion, the present study employed religious groups, non-religious groups, and delinquent group as subjects. Number of
TABLE 3

Sex difference of $\mathrm{G}$ score

\begin{tabular}{l|cc|c}
\hline G score & $\mathrm{m}$ & $\mathbf{f}$ & Total \\
\hline High & 42 & 50 & 92 \\
Low & 48 & 13 & 61 \\
& $\chi^{2}=36.20$ & $p<.005$ &
\end{tabular}

the $S \mathrm{~s}$ is shown in Table 1. Christian group is from two theological seminaries, Tenriism $S \mathrm{~s}$ are the students of Tenri University, Buddhism group is from Buddhism course of Komazawa University, non-religion group is comprized of the students of Tokyo Metropolitan University and delinquent group is from Tokyo Juvenile Classification Office. These $S_{\mathrm{s}}$ were used in all the following studies.

Procedure. Guilt feeling measure: The response to each item of SCT was rated by a 5point-scale according to the strength of guilt feeling each $S$ had as follows (least guilt-1, medium guilt-3, strongest guilt-5). Mean rating of 20 items was then calculated as guilt feeling score (G score) for each $S$. These also ranged from 1 to 5 . Some responses were based upon external sanctions as well as inner guilt feeling. For example, some $S$ s wrote stories in which they related that they restrained acts of misconduct for fear of punishment or they acted from being aware of the presence of others. Consequently, if the response was based on the fear of punishment, then it was assessed as Fear response (marked F), and the response based on the awareness of others was assessed as Shame response (marked S) as well as they were rated by 5 -point scale. The criteria of rating were decided by 6 judges (postgraduate students). After they rated independently each item of 20 random sampled cases, they discussed the matter until they reached agreement. In this experiment, 2 raters rated all the cases according to the criteria. The concordance between raters was $r=.86$ $(p<.01)$. For the test of rating reliability, they rated 20 random sampled cases after 5 months and the rate-rerate correlation was computed. It was $.85(p<.01)$ for the rater $A$, and .87 $(p<.01)$ for the rater B. Inter-group difference and sex difference of guilt measure, G. score, 
TABLE 4

Group difference of $\mathrm{S}$. response

\begin{tabular}{l|rrrrrr|r}
\hline & C & T & B & Gm & Gf & D & Total \\
\hline with S. $\dagger$ & 9 & 12 & 3 & 19 & 14 & 19 & 76 \\
without S.t† & 28 & 15 & 8 & 25 & 20 & 21 & 117
\end{tabular}

$\uparrow$ Number of $S s$ who had more than one $S$. response.

It Number of $S \mathrm{~s}$ who had no $S$. response.

TABle 5

Group difference of F. response

\begin{tabular}{l|rrrrrr|r}
\hline & C & T & B & Gm & Gf & D & Total \\
\hline with F. $\dagger$ & 1 & 4 & 1 & 8 & 6 & 8 & 28 \\
without F. $+\dagger$ & 36 & 23 & 10 & 36 & 28 & 32 & 165
\end{tabular}

$\dagger$ Number of $S s$ who had more than one F. respones.

t† Number of $S$ s who had no F. response.

and $\mathrm{S}$ and $\mathrm{F}$ response were treated by $\chi^{2}$ test.

Result. Group differences of SCT responses :

In Religion groups, (C, T, and B groups) the moral standard will be more fully internalized than in Non-religion groups ( $G$ and D), therefore guilt score will be seen to be higher than in Non-religion groups. D group seems to experience less guilt feeling for the transgression of moral standard. Generally it is said that females get higher score in moral tests than male subjects, so sex differences will also be tested concerning $\mathrm{G}$ score.

From Table 2, there was significant intergroup difference $(p<.005)$. As it was predicted above, the Religion group (hereafter referred to as $\mathrm{R}$ group) got a higher $\mathrm{G}$ score than $\mathrm{G}$ group $(p<.01)$, and $\mathrm{G}$ group got a higher $G$ score than $D$ group $(p<.005)$. The score of $\mathrm{D}$ group was lower than those of any other groups, and $C$ group got a higher $G$ score than all the other groups except B group.

The result of the sex difference is shown in Table 3. Female $S$ s got significantly higher $G$ score than male $S$ s, from which $D$ group was excluded because of its extreme low $\mathrm{G}$ score $(p<.005)$. It was
TABle 6

Factor loadings after rotation

\begin{tabular}{rrrl}
\hline Item No. & $I^{\prime}$ & II & $h^{2}$ \\
\hline 1 & .193 & .616 & .417 \\
2 & .160 & .411 & .195 \\
3 & .292 & .093 & .094 \\
4 & .202 & .476 & .227 \\
5 & .131 & .453 & .222 \\
6 & -.004 & .388 & .150 \\
7 & .171 & .307 & .123 \\
8 & .294 & -.106 & .097 \\
9 & .307 & .498 & .342 \\
10 & .238 & .103 & .067 \\
11 & .558 & .293 & .397 \\
12 & .445 & .064 & .202 \\
13 & .555 & .070 & .313 \\
14 & .353 & .126 & .140 \\
15 & .200 & .493 & .283 \\
16 & .080 & .244 & .065 \\
17 & .562 & .165 & .343 \\
18 & .380 & .107 & .156 \\
19 & .077 & .303 & .098 \\
20 & .381 & -.164 & .172 \\
& & &
\end{tabular}

found that female $S$ s in G group (hereafter referred to as $\mathrm{Gf}$ ) got higher $\mathrm{G}$ score than male $S \mathrm{~s}$ in the group (referred to as $\mathrm{Gm}$ ) $(p<.01)$. However, there was no sex difference in $\mathrm{C}$ group.

There were not so many shame responses and fear responses that groups were compared with each other with regard to number of $S$ s who had shame or fear responses as over against those who had no such responses. As the result, the number of $S \mathrm{~s}$ who had $\mathrm{S}$ responses in $\mathrm{C}$ group tended to be fewer than in $T, G m, D$ group (Table 4). Besides, $\mathrm{C}$ group tended to have fewer $F$ responses than $G$ and $D$ groups (Table 5 ). 3. Factorial structure of guilt feeling

Procedure. The procedure of factor analysis in R-technique is as follows : inter-correlations of 20 items of SCT $(20 \times 20)$ were computed by $\varphi$ coefficient, and factor analysis was performed according to Thurstone's complete centroid method. The extracted factors were rotated by orthogonal rotation method. 
Result. Two centroid factors were extracted from the intercorrelation matrix of SCT items. Those factors were statistically significant according to Tucker's criterion. The factor matrix was orthogonally rotated so that a simple structure was obtained. As shown in Table 6, those items whose factor loading after rotation exceeded .400 were as follows: Factor I-Nos. 11, 12, 13, 17. Factor II-Nos. 1, 2, 4, 5, 9, 15. The contents of the situations which had high loading for Factor I mostly deals with sexual desires. As for Factor II, they are offences against public morality, violations of the law, etc. Consequently Factor I will be interpreted as "impulsiveness", and Factor II will be interpreted as "illegality".

\section{PART II}

\section{Procedure}

Child rearing measure: Slater's (1962) $\mathrm{Pa}$ rental Role Pattern Questionnaire was administered with some modifications and abridgments as the rearing measure. Slater's PRP consists of 2 scales. One is ESW (emotional supportiveness and warmth) in which the items reflect parents' help, reward, and affection. The other is IDD (inhibitory demands and discipline) in which the items show their strictness, authority, and demands. Four types of child rearing were classified from the combination of ESW and IDD - Type A (ESW and IDD high), type B (ESW high, IDD low), type C (ESW low, IDD high), and type D (both scales low). From the research findings which some authors have pointed out, it will be predicted that rearing type A (Affectionate and disciplining) has positive relationships with $G$ score. Group difference of rearing types and the relationship between $\mathrm{G}$ score and rearing type is treated by $\chi^{2}$ test and $\varphi$ coefficient respectively.

Personality measure: Rosenzweig's Picture Frustration Study was used as the personality measure, since, as Arnold (1960) suggests, general intropunitive tendency seems to have some relationship with guilt feeling. PFT measures such as Extrapunitive, Intropunitive, Impunitive and Obstacle-dominant, Egodefen-
TABLE 7

The relationship between rearing type and $\mathbf{G}$ score

\begin{tabular}{|c|c|c|c|c|c|}
\hline \multirow{2}{*}{$G$ score } & \multicolumn{4}{|c|}{ Rearing type } & \multirow{2}{*}{ Total } \\
\hline & A & $\mathrm{B}$ & $\mathrm{C}$ & $\mathrm{D}$ & \\
\hline High & 28 & 26 & 24 & 19 & 97 \\
\hline \multirow[t]{2}{*}{ Low } & 22 & 24 & 28 & 22 & 96 \\
\hline & & 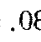 & & & \\
\hline
\end{tabular}

The relationship between rearing and $\mathrm{G}$ score

\begin{tabular}{c|cc|c}
\hline \multirow{2}{*}{ G score } & \multicolumn{2}{|c|}{ Item } & No. 13 \\
& Yes & No & Total \\
\hline High & 46 & 24 & 70 \\
Low & 33 & 41 & 74 \\
& & & \\
& & & \\
& & &
\end{tabular}

sive, and Need-persistent were related with guilt variable ( $\mathrm{G}$ score) by $\varphi$ coefficient.

Life attitude measure: Kluckhohn's (1961) value orientations were used with abridgement for life attitude variable. It consists of 5 orientations. Those are (a) activity orientation, (b) time orientation, (c) relational orientation, (d) man-nature orientation and (e) human nature orientation. A general value orientation which corresponds roughly to Spranger's value systems was also added. The association between life attitude and $\mathrm{G}$ score was computed by $\varphi$ coefficient.

\section{Results}

Factor of child rearing. There were no significant group differences concerning the patterns of child rearing. Although some investigators have suggested a positive relationship between child rearing factor and the tendency to experience guilt feeling, there was no relationship between the 4 types of rearing considered and $\mathrm{G}$ score $(C=.08)$ (Table 7).

The relation between $\mathrm{G}$ score and ESW scale only was tested, but no relationship was obtained. The same was true of the relation between IDD scale and $\mathrm{G}$ score. 
TABLE 9

The relationship between Extrapunitive personality and $\mathrm{G}$ score

\begin{tabular}{c|cc|c}
\hline \multirow{2}{*}{ G score } & \multicolumn{2}{|c|}{$\mathrm{E}$} & Total \\
& Hight & Low & \\
\hline High & 35 & 62 & 97 \\
Low & 63 & 33 & 96 \\
& & & \\
& $\varphi=-.295$ & $p<.005$
\end{tabular}

$\dagger S$ s who got more than 34.7 , median of Extrapunitive score, were grouped as "High".

In the next place, relationships between each item of the rearing questionnaire and $\mathrm{G}$ score were tested. Among many combinations, item No. 13 only was significantly related with $\mathrm{G}$ score. From Table 8, the $S$ s who answered "yes" to No. 13: "I received severe training in the childhood," tended to have higher $\mathrm{G}$ score $(p<.025)$. It was found, however, that $\mathrm{G}$ group $S \mathrm{~s}$ got the highest $\mathrm{G}$ score, as stated above, and at the same time they answered "yes " to No. 13 significantly more often than any other groups. Consequently, above mentioned relationship might appear quite natural. Unless that relationship was also verified within every group, it could not be emphasized. As the result, in $\mathrm{G}$ group, too, $S \mathrm{~s}$ who answered that they had recieved severe training tended to get high $\mathrm{G}$ score $(p<$ $.10)$.

Factor of Personality. It is hypothesized that those who have intropunitive personality seem to be more vulnerable to guilt feeling, and to experience it more easily. On the contrary, the extrapunitive will tend to shift responsibilities to others and to feel guilty less than the intropunitive. However, it will be hypothesized that the suggested relationship between personality and guilt feeling will be seen more often in Non-religion groups than in Religion groups in which moral norm is more established.

1. Extrapunitive (E): There was no group difference regarding extrapunitive personality. It was found from Table 9
TABLE 10

The relationship between Intropunitive and $\mathrm{G}$ score

\begin{tabular}{l|cc|c}
\hline \multirow{2}{*}{ G score } & Hight & Low & Total \\
& 57 & 40 & 97 \\
\hline High & 41 & 55 & 96 \\
Low & & & \\
& $\varphi=.161$ & $p<.05$ &
\end{tabular}

$\dagger$ Ss who got more than 28.5, median of Intropunitive, were grouped as "High".

TABLE 11

The relationship between Impunitive and $\mathrm{G}$ score

\begin{tabular}{l|cc|c}
\hline \multirow{2}{*}{ G score } & High† & Low & Total \\
& 58 & 39 & 97 \\
High & 37 & 59 & 96 \\
Low & & & \\
& $\varphi=.213$ & $p<.005$ &
\end{tabular}

$\dagger S \mathrm{~s}$ who got more than 35.9 , median of Impuitive, were grouped as "High".

that there was significant negative association between extrapunitiveness and $\mathrm{G}$ score, $(\varphi=-.295, p<.005)$. That is, the high extrapunitive person seems to get low $G$ score. This relationship was also verified in each group except group B. In groups $\mathrm{C}$ and Gf, however, the intra-group association between $\mathrm{G}$ score and extrapunitiveness was not so high $(p<.10)$.

2. Intropunitive (I): Gf group $S$ s were shown to have significantly higher intropunitive personality than other groups. As shown in Table 10, the hypothesis concerning the positive relationship between intropunitiveness and $\mathrm{G}$ score was supported $(\varphi=.161, p<.05)$. Consequently, it was proved as suggested above that the intropunitive tended to have higher $G$ score. This relation was verified in $T$, $\mathrm{Gm}$ and Gf groups, too, though not so sharply as the extrapunitive.

3. Impunitive (M): As for the group differences, Gf and D Group $S$ s tended to have lower impunitiveness than the other 
TABle 12

The relationship between Obstacledominant and $\mathrm{G}$ score

\begin{tabular}{l|cc|c}
\hline \multirow{2}{*}{ G score } & \multicolumn{2}{|c|}{ O-D } & Total \\
& High $\dagger$ & Low & \\
\hline High & 43 & 54 & 97 \\
Low & 55 & 41 & 96 \\
& & & \\
& & &
\end{tabular}

$\dagger$ Ss who got more than 17.6, median of $\mathrm{Ob}$ stacle-dominant, were grouped as "High".

TABLE 13

The relationship between general value orientation and $G$ score

\begin{tabular}{|c|c|c|c|}
\hline G score & $a, b, c, d \dagger$ & $e, f$ & Total \\
\hline High & 35 & 51 & 86 \\
\hline Low & 73 & 18 & 91 \\
\hline & $\varphi=.406$ & .005 & \\
\hline
\end{tabular}

$\dagger S$ s who chose a, b, c, d were combined, and $\mathrm{e}$ and $f$ were likewise combined.

groups. From Table 11, there was positive relationship between impunitiveness and $\mathrm{G}$ score $(\varphi=.213, p<.005)$. The tendency that the more impunitive, the higher the $G$ score was also found in $D$ group.

4. Obstacle-dominant (O-D) : From Table 12, a slight negative relationship was found between O-D and G score, $(\varphi=$ $-.129, p<.10)$. That is, $S \mathrm{~s}$ having O-D tended to get low $\mathrm{G}$ score. As for the intra-group association, there were the same negative tendencies in $\mathrm{T}$ and $\mathrm{D}$ groups.

Factor of life attitude. The general value orientation and Kluckhohn's 5 value orientations were used as life attitude measures, and they were associated with $G$ score.

1. General value orientation: This consisted of 6 items, (a) becoming rich, (b) winning fame in the world, (c) just living the life that suits one's own tastes, (d) living cach day as it comes without worrying, (e) resisting the evils in the world and living a pure life, and ( $f$ ) giving everything in the service of society.
TABle 14

Group difference of response toward general value orientations

\begin{tabular}{l|rrrrrr|r}
\hline & G & T & B & Gm & Gf & D & Total \\
\hline a, b, c, d & 5 & 12 & 5 & 31 & 23 & 32 & 108 \\
e,f & 21 & 14 & 5 & 12 & 10 & 7 & 69 \\
& $\chi^{2}=32.53$ & $p<.005$
\end{tabular}

Items (e) and (f) seem to be quite different from the others. It may be hypothesized that those who choose items (e) or (f) will have well established moral norms and so get higher $G$ score. From Table 13 there was a marked relationship between the general value orientation and $\mathrm{G}$ score. $S$ s who chose (e) or (f), that is, whose life attitude was oriented to a pure life or the service of society, tended to get higher $G$ score as suggested above. In the next place, there was significant group difference in the response to general value orientation. From Table 14, C group $S$ s whose average $\mathrm{G}$ score was highest tended to choose (e) and (f) type, and $\mathrm{D}$ group $S \mathrm{~s}$ whose average $\mathrm{G}$ score was lowest mostly chose (a), (b), (c), and (d) type. Consequently, the relation between the general value orientation and $G$ score might be quite natural and can not be emphasized unless there are the same tendencies within each group.

In reality, the same relation between the two variables was found in three groups; C group $(\varphi=.569), T$ group $(\varphi=.381)$ and $\mathrm{G}$ group $(\varphi=.232)$. From this result, it may safely be said that there is a certain relation between value orientation and guilt feeling.

2. Activity orientation: This consists of the two attitudes toward one's job, that is, (a) accomplishing things and doing some worthwhile works, and (b) working in the ways that best suit the subject, in enjoying life as he goes along. It may be hypothesized that those who select (a) type will get higher $G$ score than those who select (b), which seems to be more easygoing attitude. In reality, however, the 
TABle 15

The relationship between activity orientation and $G$ score within $G$ group

\begin{tabular}{l|cc|c}
\hline G score & $\mathrm{a}$ & $\mathrm{b}$ & Total \\
\hline High & 17 & 10 & 27 \\
Low & 17 & 34 & 51 \\
& & & \\
& $\varphi=.284$ & $p<.025$ &
\end{tabular}

TABLE 16

The relationship between time orientation and $\mathrm{G}$ score

\begin{tabular}{l|cc|c}
\hline G score & $\mathrm{a}, \mathrm{c}$ & $\mathrm{b}$ & Total \\
\hline High & 70 & 22 & 92 \\
Low & 58 & 37 & 95 \\
& & & \\
& $\varphi=.161$ & $p<.05$ &
\end{tabular}

hypothesis was not proven for the combined whole group. From Table 15, it was supported only within G group $(\varphi=.284)$.

3. Time orientation: This consists of three items, (a) traditional ways are the best, (b) giving most attention to what is happening in the present, and (c) the best way is to look a long time ahead, and working hard for a better future. It will be hypothesized that the past oriented and the future oriented type may get higher $G$ score than the realistic way of living.

The result is shown in Table 16 that there was a significant relation between time orientation and $\mathrm{G}$ score as suggested above $(\varphi=.161, p<.05)$. However, there was a marked group difference in the response to time orientation, and the Religion group was inclined to take the future orientation $(p<.005)$.

Then intra-group associations between time orientation and $G$ score were computed, but no relation was found within any groups. Consequently, the relation between time orientation and $\mathrm{G}$ score for the whole group seemed to come directly from the fact that Religion group which received the higher $\mathrm{G}$ score tended to take the past oriented and future oriented type.

4. Relational orientation: This con-
TABLE 17

The relationship between relational orientation and $G$ score

\begin{tabular}{c|cc|c}
\hline G score & $a$ & $b, c$ & Total \\
\hline High & 14 & 79 & 93 \\
Low & 29 & 67 & 96 \\
& $\varphi=.181$ & $\hat{y}<<.025$ &
\end{tabular}

sists of three items ; (a) not taking part in decision, just depending on the boss to help him in many ways, (b) working together without a main boss, all the men counting on each other, and (c) working on one's own as an individual.

Dependent persons in the inter-personal relationship will be hypothesized to obey easily the internalized moral norm and then get the high $\mathrm{G}$ score.

From Table 17, there was significant relationship between relational orientation and $\mathrm{G}$ score, but it was of quite opposite direction, that is, the dependent persons seem to get a lower $G$ score. However, there were no intra-group associations in any group.

An inspection of the group difference of the response to relational orientation showed that $D$ group tended to choose (a), that is, the dependent type. Consequently the relation found above seemed to come directly from the fact that $\mathrm{D}$ group got very low $G$ score and that they were mostly dependent type.

5. Man-nature orientation: This orientation was tested by the way of thinking toward life span. The items are as follows : (a) Every person has a set time to live, and when that time comes, it just comes; and (b) The life span can be made longer according to the development of science.

There was significant group difference in responses to the man-nature orientation, that is, G group mostly chose (a), and G and $\mathrm{D}$ groups were not so deterministic. No relation, however, was found between the attitude toward the life span and $G$ score.

6. Human nature orientation: This is 
TABLE 18

The relationship between human-nature orientation and $G$ score

\begin{tabular}{l|rrrr|c}
\hline G score & a & b & c & d & Total \\
\hline High & 29 & 25 & 24 & 10 & 88 \\
Low & 22 & 9 & 41 & 17 & 89 \\
& \multicolumn{3}{c}{$C=.278$} & $p<.01$ &
\end{tabular}

the question of what the character of innate human nature is. It consisted of 4 items. They are the following: (a) human nature is good, (b) it is good-and-evil, (c) evil, (d) neutral, that is, neither good nor evil. An interesting result was gained from the distribution of the response to human nature orientation. G group mostly took (c), that is, man is intrinsically evil, $\mathrm{T}$ group tended to take (a), good. B group chose (a) and (b), that is, man is good and/or good-and-evil, G group chiefly chose (a) and (b), and a few of them chose (d) which is the neutral view. The majority of D group took (b) and some of them took (a) and (d).

As for the relationship between human nature orientation and $G$ score, it was found from Table 18 that those who got the high G score tended to choose "good" and "evil", and that those who got the low $\mathrm{G}$ score seemed to choose the intermediate position that is, "good-and-evil" and/ or "neither good nor evil".

Since C group tended to take "evil" position and T group "good", the relation was tested only for Non-religion group. The result is, those who chose the "good" position tended to take rather higher $G$ score.

\section{Discussion}

Analysis of SCT response: There were marked group differences among $\mathrm{R}, \mathrm{G}$ and $\mathrm{D}$ group as predicted. Most striking is that $\mathrm{C}$ and $\mathrm{D}$ groups were deviated extremely, though in the opposite direction. $\mathrm{R}$ group got higher $\mathrm{G}$ score than any other groups, but it may be due mostly to $\mathrm{G}$ group. Further research which includes a broader range of religion should tend to clarify this point.

As for the sex difference, female $S$ s showed higher $\mathrm{G}$ score than did the male as has sometimes been said. Hoffman (1963) says, for example, that this may not be because women are more moral than men but because the female's sex role exerts less pressure toward deviation and also provides less opportunities for it. Though it is not clear from the present data whether he is right or not, it was shown that female $S$ s felt guilt more easily. As for $\mathrm{C}$ group, however, there was no sex difference, and both of them got very high $G$ score.

Factor Analysis: 2 factors, "impulsiveness" and "illegality" were tentatively extracted by factor analysis. Present author had previously had 5 postgraduate students categorize subjectively the 20 items of SCT. They were as follows; Category I was composed of item numbers $1,2,4,5,6,9,15$, and 19, which mostly dealt with unlawful behaviors or offences against public morality. Category II consisted of Nos. 3, 7, 8, 10,17, 18, 20, which mainly dealt with troubling others. And Category III consisted of Nos. 11, 12, 13, which were concerned with sex. As the result, Category III seemed quite coincident with Factor I, and Category I with Factor II (cf. Table 6). Consequently, some of those hypothetical categories might be supported by the result of factor analysis, and it may safely be said that they feel guilty easily for sexual, impulsive behaviors and illegal conducts. However, those 2 factors would not be sufficient to determine the factorial structure of guilt feeling. Especially the factor which corresponds with Category II is not extracted yet. Further studies are necessary for this respect.

Factor of training: Some authors such as Allinsmith (1960), and Whiting (1953) have said that love-oriented or psychological training would contribute to severe guilt, but the present study revealed no such relation. It seems rather that those who recognize themselves to have received 
severe training in childhood are prone to feel guilty. The reason why the clear-cut relation between training factor and guilt feeling was not obtained may be as follows : First, there were some deviations in the distribution of the score of the child rearing scale, that is, they tended to get higher score for ESW and lower score for IDD. Second, there seemed to be some confusion between the father role and the mother role, for their roles were not set apart in the questionnaire. Only the parents' attitude of training was asked. Further study is necessary for the factor of training.

Factor of personality: The intropunitive who are apt to take responsibility in frustrating situations are shown to have higher guilt consciousness as predicted. This is supported by the negative relation of the extrapunitive with guilt feeling. The impunitive personality which is characterized by the repression of aggression or tolerating the frustrating agent related to severe guilt. As the result there seems to be quite consistent relation between personality assessed from PFT and guilt feeling. As for the hypothesis that relationship between personality and guilt feeling is not so remarkable in Religion groups as in Non-religion groups, $\mathrm{C}$ group showed just a slight relation between extrapunitive and $G$ score, but there was no significant relation for other indices. Consequently the severity of guilt in $\mathrm{C}$ group may be due to factors other than personality. But since Extrapunitive, Intropunitive and Obstacledominant are related to severe guilt in $T$ group, the hypothesis can not be extended to religion in general.

Factor of life attitude: As for the general value orientation, those who orient toward a pure life or the service for society were related to severe guilt, both in the whole mixed group and within each group. Concerning the activity orientation, those who take the positive, not easy-going attitude toward their jobs were shown to have higher guilt, though only in $\mathrm{G}$ group. Further, in the time orientation, high guilt was related to persons who worked for a better future, not realistically oriented. From those results, those who have, as it were, the " sincerity attitude" seem to have moral norms established and experience severe guilt for the transgression of the norm.

Concerning the relational orientation, contrary to the prediction, the submissive, dependent persons were negatively related to guilt, though slightly. It may be interpreted that the submissive persons might act according to the other-oriented norms. In reality there were more dependent types in $\mathrm{D}$ group. Moreover, many shame and fear responses were found in D group, too. There was no evident relationship between man-nature orientation and guilt feeling. This may be due to the fact that most $S \mathrm{~s}$, except $\mathrm{C}$ group, believed in the development of science and took the masteryover-nature orientation. As for the human-nature orientation, those who viewed man as intrinsically good or evil tended to have more severe guilt consciousness than those who took the intermediate position. The latter may be tentatively interpreted as a somewhat more ambiguous, loose attitude than the former which views man very strictly or believes in man's bona fides. Consequently those who take the intermediate view may change their conducts according to the situations without experiencing severe guilt feeling.

\section{REFERENCE}

Allinsmith, W. 1957 Conscience and Conflict: The moral force in personality. Child Developm., 28, 469-476.

Allinsmith, W. 1960 The learning of moral standards. In D. R. Miller \& G. E. Swanson (Eds.), Inner confict and defence. New York: Henry Holt.

ARnold, M.B. 1960 Emotions and personality. Vol. 2. New York : Columbia University Press.

Ausubel, D. P. 1955 Relation between shame and guilt in the socializing process. Psychol. Rev., 62, 378-390.

Benedict, R. 1946 The chrysanthemum and the sword. Boston: Houghton Mifflin.

Hoffman, M. L. 1963 Child rearing practices 
and moral development. Child Developm., 34, 295-318.

Kluckhown, F. R., \& Strodtbeck, F. L. 1961 Variations in value orientations. Illinois: Row, Peterson.

Mryoshr, M. (Ed.) 1962 Psychology and factor analysis, Tokyo: Seishin Shobo.

Mowrer, O. H., Ellis, A., Gurrun, C. A., \& SHoben, E.J. 1960 The role of the con- cept of $\sin$ in psychotherapy. 7 . couns. Psychol., 7, 185-201.

Slater, P. E. 1962 Parental behavior and the personality of the child. 7 . genet. Psychol., 101, 53-68.

Whrting, J.W. M. 1953 Child training and personality. New Haven: Yale University Press.

(Received May 6, 1966) 